risk $(A R)=18.5 \%)$ and death $(R R=4.56,95 \%$ CI 2.05 to 10.16 , $\mathrm{AR}=39.0 \%$ ). Opposite-direction (adjusted $\mathrm{OR}(\mathrm{aOR})=8.01$, $95 \%$ CI 2.34 to 27.68 ) and RTCs on wet surfaces ( $\mathrm{aOR}=10.43$, 95\% CI 1.38 to 79.15 ) were significantly associated with HWZ crashes.

Conclusion These results indicate that traffic separation in work-zones should be prioritised to reduce the increased burden of crashes in LICs.

\section{BURDEN AND FACTORS ASSOCIATED WITH WORK-ZONE CRASHES ON AN INTERURBAN HIGHWAY IN PAKISTAN}

J A Bhatti*, J A Razzak, E Lagarde, L Salmi Correspondence: Equipe Prvention et Prise en Charge des Traumatismes, Institut National de la Sant et de la Recherche Mdicale INSERM U897, Universit Victor Segalen Bordeaux 2146 Rue Lo Saignt Bodrdeaux, 33076, France

10.1136/ip.2010.029215.565

Introduction Highway work zones (HWZ) may lead to an increased road traffic crash (RTC) risk. Little is known about such crashes in low-income countries (LICs).

Objective To assess burden and factors associated with HWZ crashes on a highway in Pakistan.

Methods Police reported crashes occurring on Karachi-Hala road-section from Jan 2006 to Dec 2008 were included in this study. We compared crash and death risk between work and normal traffic zones for a $50-\mathrm{km}$-long road-section for which data was available on work zone dates and average daily traffic. Crash locations were described for a further $146-\mathrm{km}$-long section on which we assessed factors associated with HWZ crashes.

Results Of 180 crashes, 27 (15\%) occurred in HWZs accounting for $30.8 \%$ of road fatalities ( $N=91$ ). HWZ exposition was one-sixth of the whole traffic exposition on the selected road section. Rates were higher in HWZ compared to other parts of the road for crash $(R R)=2.28$, (95\% CI 1.14 to 4.56$)$, attributable 